\title{
Influence of the green-machining parameters on the mechanical properties of alumina rods
}

\author{
Alexandre Margarido ${ }^{1}$ Benedito Moraes Purquerio ${ }^{1}$ - Cesar R. Foschini ${ }^{2}$. \\ Carlos Alberto Fortulan ${ }^{1}$
}

Received: 23 March 2016 / Accepted: 15 June 2016 / Published online: 22 June 2016

(C) Springer-Verlag London 2016

\begin{abstract}
Green and white machining has being extensively employed in compact blanks to obtain a pre-form prior to the sintering of advanced ceramics. Both machining processes involve low-energy consumption and high material removal capacity. Green machining is more sustainable than white machining; however, its use should be more demanding because of the complex binder links between ceramic powders. The goal of this work is to identify the limits of aggressive cutting through measures of machining forces on green specimens and its correlation with the mechanical properties of sintered alumina rods. Rod specimens were obtained from aluminaPVAl granules compacted at 100 and $200 \mathrm{MPa}$, thermal annealed and green machining employing a head with aerostatic bearings. Gradual introduction of critical defects on the surface due to the action of the wheel was detected. Surface without damage was detected with a material removal rate of $10,000 \mathrm{~mm}^{3} / \mathrm{min}$ and with power consumption of $1700 \mathrm{~W}$. The speed limit that was identified resulted in the rupture of the specimen, depending on the depth of cut, which exceeded the mechanical strength. The correlation between power consumption and rate of removal proved to be critically important processing parameters for the design of machining in green ceramic.
\end{abstract}

Carlos Alberto Fortulan

cfortula@sc.usp.br

1 Department of Mechanical Engineering, University of Sao Paulo-USP, Avenida Trabalhador São Carlense 400-Centro, São Carlos, SP 13560-970, Brazil

2 Department of Mechanical Engineering, Sao Paulo State University-UNESP, Bauru, Avenida Engenheiro Luiz Edmundo C. Coube 14-01-Vargem Limpa, Bauru, SP 17033-360, Brazil
Keywords Green machining · Critical defects · Ceramic manufacturing · Grinding ceramic

\section{Introduction}

Green machining is a classical industrial process used for manufacture of spark plugs, thimble-shaped lambda sensors, and ceramic filters applying grinding process in large ceramic companies. Recently, aided by CNC technology, green machining has been used to obtain customized complex shapes in especially medical and technological applications such as orthopedic, dental crowns, where bio-ceramics have been widely introduced [1-5]; this trend has enabled manufacture by small technology-based companies or even, multidisciplinary laboratories.

A mold-free customized product can be obtained based on the "near-net shape" concept, which facilitate the production of complex parts with highest possible structural strength. Green machining is reliable when combined with the removal of defects introduced during the formation processes and the correction of distortion due to density gradient [6-8].

The key feature is its low-energy consumption per volume removed and the large capacity of material removal, which does not require expensive high-wear resistant tools, and the machining can be done by numerical control (CNC) using a single-point tool or grinding wheel pre-formed in creep feed grinding. However, the rate of material removal is limited due to the low mechanical strength that these components present in this "non-sintered" state, which is generally less than 2.0 MPa. This issue was addressed by Kamboj et al., who have found that milling could be performed on green gelcast ceramic compacts with reasonably low forces [9]. In his classic text, Reed presents that aspects related to the low cutting forces that a green piece resist and adapted from hard 
machining pointed out that increasing cutting pressure, the mechanism of material removal undergoes an initial phase of intra-agglomerate fracture to a mixed phase and subsequently inter-agglomerate phase, which causes greater surface damage [10].

The term green machining is used generically for machining of green and pre-sintered bodies; the last one is properly named white machining. However, the cutting mechanisms involved are different; when performing white machining, microcracks occur through a process of brittle fracture in the weak bonds around the new necks formed between particulates.

In order to obtain green ceramic compacts, shaping via dry pressing requires that addition to the powders of binders, plasticizers, and lubricant to reduce brittleness and improve the machining characteristics of the green ceramic. Typically chosen from either polyvinyl alcohol (PVA) as applied by Chabert et al. or acrylic to increase the structural strength of the blank [11], $\mathrm{Wu}$ and Mcanany pointed out the benefit of acrylic binders for green machining [12]. The powder must be agglomerate in coarse granules and the mechanism that govern the material removal of the compacted green is influenced for variables, besides the material characteristics, such as particle size, granulation method, agglomerates size, binder (type and concentration), and humidity. Due to the organic bond between the alumina particles, the material removal process is characterized by the formation of ductile chips more than by brittle fracture, which enables the production of surfaces free of chipping if machining conditions are well controlled; however, it promotes stickiness on the grinding wheel surface, requiring permanent maintenance of its surface. Another advantage is that the chip from machining can be directly reused in the previous step of mixing and milling, making it more sustainable process.

So as to achieve on efficient cutting process with a uniform quality, the rate of material removal can be increased by increasing the depth of cut and cutting feed, which was recently reported by Jahanmir et al. [13]. However, it is very difficult to predict whether a green body will support green machining and the best strategy for the implementation of worker; beyond the normal limits of material removal, defects are introduced and loss of quality occurs, and this quality is very difficult to quantify during machining or even in green bodies [14]. However, Fortulan et al. reported loss of mechanical properties in porcelain billets green machined at industrial conditions with any increasing aggressiveness of cutting; i.e., either by increasing the feed speed or by the material removal rate, $25 \%$ loss of mechanical properties of sintered pieces just with increasing intensity of green machining attributed to the change of the material removal mechanism were found in their study [15].

Desfontaines et al. propose a criterion of machinability of the green compacts, in order to optimize the green body's behavior during machining, where important parcel was assigned to the generated flakes, since the flake generation is usually considered as a major problem and may lead to scrapping of the body [14].

On the other hand, the work of Jahanmir et al. based on roughness analysis emphasizes that the depth of cut has little influence on the final quality of the green ceramic surface [13]. Therefore, it can be increased by offering low risk of damaging to the surface, resulting in the reduction of machining time. Another advantage of increasing the feed speed is the reduction of tool wear. This can be fully explored in grinding operations and is limited only by the maximum available speed of the spindle. However, due to limitations imposed by the material strength and efforts imposed by increasing centrifugal forces, feed speed cannot be increased indefinitely.

The grinding processing applied in green machining, though extensively used in large industries with empiricalbased technology [14], considering new models of business with customized products and production, suffers from a lack of information regarding appropriate parameters for its optimization. The selection of grinding wheels and tip-mounted grinding and the careful analysis of critical defects introduced during machining require more research in this area.

The main goal of this work is to identify the limits of aggressive cutting in maintaining the integrity of the alumina body with an economic output by assembling of a data acquisition system to measure the machining efforts. Grinding machining was performed, in which measurements of torque and grinding wheel peripheral speed were evaluated as critical model parameters to predict the optimum combination of machining efforts. Also, the influence of compaction pressure and thermal treatment applied after compacting was evaluated.

\section{Experimental procedure}

For the realization of the work, external cylindrical grinding of rods was carried out; the reasons are as follows: this process is considered a standard; cylinders do not have edges, which concentrate stress that may interfere with the results; and the results may be exported to mounted points, taken as a tendency for customized parts. For that, a bench test was designed for acquisition of experimental data for measuring the threshold torque supported by the specimen without introducing any critical structural damage to the analyzed samples. Figure 1a displays a schematic drawing of the test equipment, and Fig. 1b shows an actual photograph of the equipment. The headstock, displayed in Fig. 1c, d, was developed to provide sufficient torque to operate and hold a torque meter between the motor system and the ceramic specimens. A torque sensor MKDC-5 was used with maximum capacity of $5 \mathrm{Nm}$ from MK Control and Instrumentation Ltd., and a servo motor 
Fig. 1 Schematic drawing of the bench test machining, wherein a 1 aerostatic head, 2 torque wrench, 3 green blank, and 4 servo motor; b photo of the equipment; c full design headstock; and d imagefocusing torque wrench

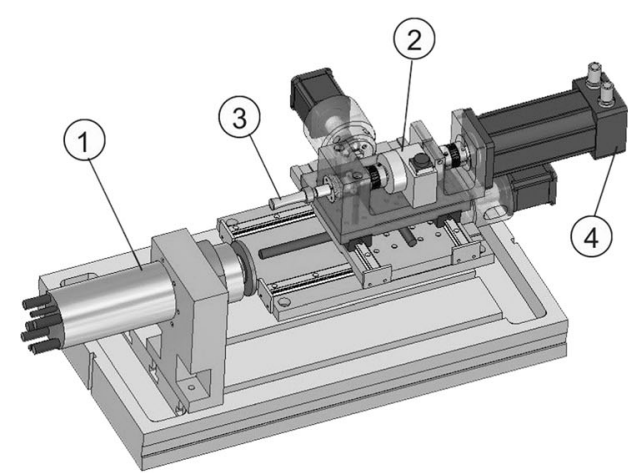

a)

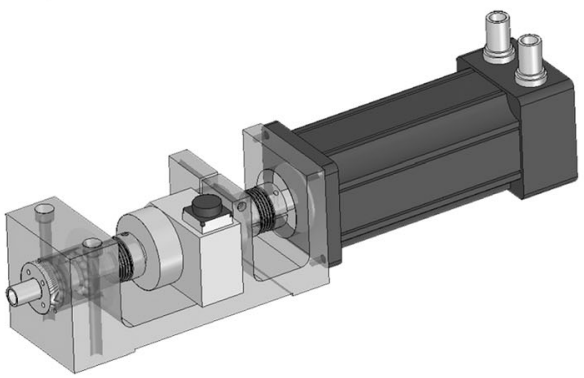

c)

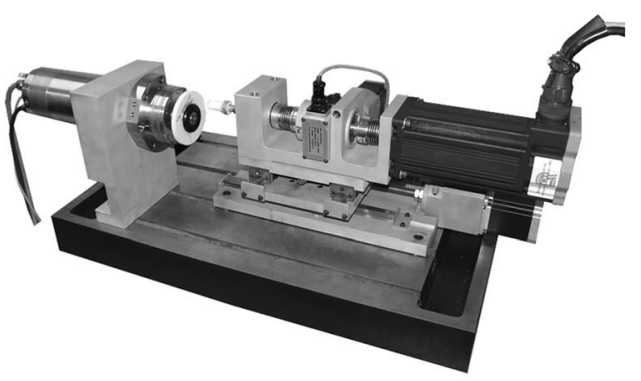

b)

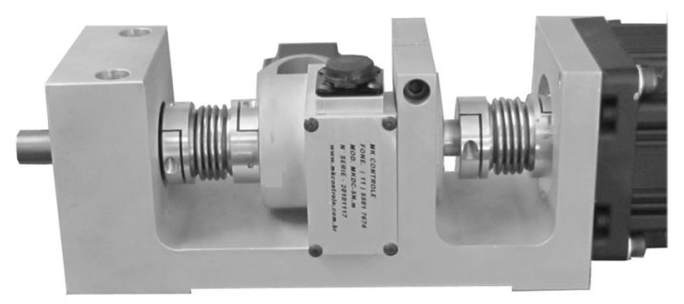

d)
(WEG SWA56-2.5-20) with a servo converter (WEG SCA050004). The data acquisition module USB-6009 (14bit resolution) from National Instruments was utilized for experimental control and data acquisition in real time during the machining. The objective was to gather information on rotation, depth of cut, and feed speed matched for optimized performance. The direct measurement of the torque using a torque meter between the drive motor and the sample was attempted. To ensure the quality of grinding, the rotation of the spindle and the specimen must remain the same throughout the process. This was achieved by a computer which controls the feed of the tool, so it does not exceed the stipulated maximum torque and the defined minimum speed. As sketched in Fig. 2, an experimental design was developed for the machining data acquisition. A dicing spindle D05716/3 of $2.4 \mathrm{~kW}$ produced by Loadpoint Bearings Limited (UK) was used as a machining head. The setup was instrumented by a drive (control head interface) of $20 \mathrm{amp}$ capable of handling rotations of up to $480,000 \mathrm{rpm}$ of synchronous and asynchronous engine and RS232 input ports and USB drive system SD2S (SIEB \& MEYER AG), compensation system for the engine head choke 11A $350 \mu \mathrm{H}$, and a manual control unit test box (SIEB \& MEYER AG).

The grinding wheels were custom made by Norton (Saint Gobain Abrasives Ltd.). The technical specification for green machining was $75 \times 6 \times 1938 \mathrm{~A} 80 \mathrm{IVH} 45 \mathrm{M} / \mathrm{S}$, where the indices represent the external diameter $\left(\varnothing_{e}\right)=75 \mathrm{~mm}$, internal diameter $\left(\varnothing_{i}\right)=19 \mathrm{~mm}$, thickness $(e)=6 \mathrm{~mm}, I$ hardness = soft, $V$ vitrified, $H$ industrial denominator (Norton), and $38 \mathrm{~A}=$ corundum white and 80 mesh size of grains for rough and finish machining. The dressing tip was made with a lapidated single crystal diamond, manufactured by Master Diamond with a lapping angle of $40^{\circ}$ and radius of $0.5 \mathrm{~mm}$. It was positioned at $45^{\circ}$ with high centered to the wheel and dressed the cutting and peripheral surface. The dressing conditions, without lubrication per pass, were depth $0.05 \mathrm{~mm}$, feed speed $100 \mathrm{~mm} / \mathrm{min}$, and rotation $1000 \mathrm{rpm}$.

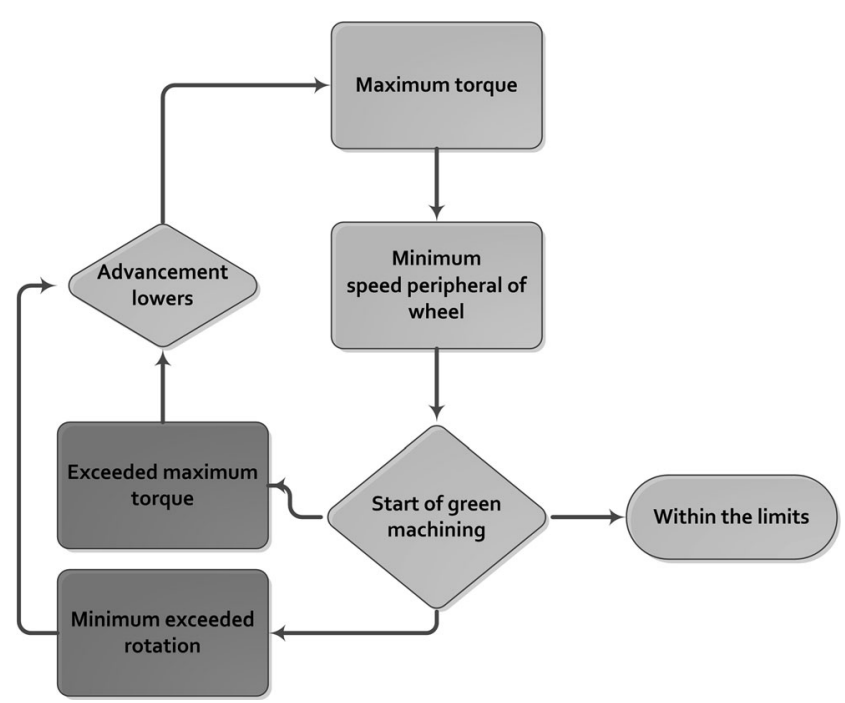

Fig. 2 Machining control 


\subsection{Ceramic specimen fabrication}

Alumina ceramic specimens, with $99.9 \%$ purity alumina, was selected for the study because its properties are considered universal and thus suitable for a case study. Calcined alumina A1000-SG (Almatis Inc.) was used with an equivalent particle diameter of $0.4 \mu \mathrm{m}$, surface area of $7.7 \mathrm{~m}^{2} / \mathrm{g}$, and theoretical density of $3.99 \mathrm{~g} / \mathrm{cm}^{3}$. The mixture and de-agglomeration of the powder were performed by wet ball milling using zirconia cylinders $(\varnothing 12 \mathrm{~mm}, h$ $12 \mathrm{~mm}$ ) as media. A suspension of 30 vol\% powder was prepared with the liquid volume comprising 68 vol\% of distilled and deionized water, 1 vol\% PVA $\left(T_{g}\right.$ of $85^{\circ} \mathrm{C}$, MW of 22,000), and 1 vol\% ammonium polyacrylate (dispersal 130). The final granulated powder was obtained by spray dryer. Sintered specimens with dimensions of $(\sim \varnothing 6 \times 50 \mathrm{~mm})$ in the form of cylinders were compacted isostatically at 100 and $200 \mathrm{MPa}$ for $30 \mathrm{~s}$, resulting in dimensions close to $(\sim \varnothing 11 \times 50 \mathrm{~mm})$. The compacted cylinder specimens were left to stand for more than $48 \mathrm{~h}$ at room temperature under regular atmospheric conditions. Out of this lot, five control samples were reserved in this state, while the remaining specimens were thermally treated in atmospheric air at $100{ }^{\circ} \mathrm{C}$ for $12 \mathrm{~h}$.

\subsection{Experimental analysis of machining process}

As a first step, the compacted cylinders were machined close to the final shape of the green specimens $\varnothing 7 \times 50 \mathrm{~mm}$ and sintered at $1600{ }^{\circ} \mathrm{C}$ for $2 \mathrm{~h}$. The cylindrical specimens were machined, varying the feed speed $\left(v_{f}\right)$ (longitudinal feed) at 100, 200,300, and $400 \mathrm{~mm} / \mathrm{min}$ and depth of cut $\left(a_{p}\right)$ at 0.5 and $1 \mathrm{~mm}$, what combined results in different rates of material removal. In all experiments, the grinding wheel peripheral speed was fixed at $45 \mathrm{~m} / \mathrm{s}$. Table 1 shows the machining conditions applied, and Fig. $3 \mathrm{a}, \mathrm{b}$ provides the photographic images of the actual machining operation of alumina cylinders with the test equipment.

\subsection{Mechanical strength}

After machining and sintering the green ceramic specimens into the shape of cylindrical rods, the tensile strength in a fourpoint flexure test (ASTM C1684-08) using an universal testing machine from EMIC with a crosshead speed of $0.2 \mathrm{~mm} /$ min and load cell of $20 \mathrm{kN}$ was monitored. Compressive strength tests were also conducted (ASTM C1424-04) for correlation with the tolerance of the machining torque. The fracture surfaces of the samples were examined by optical microscopy.
Table 1 Experimental machining conditions

\begin{tabular}{llll}
\hline $\begin{array}{l}\text { Compaction pressure } \\
\text { (MPa) }\end{array}$ & Test description & $\begin{array}{l}\text { Feed speed } \\
(\mathrm{mm} / \mathrm{min})\end{array}$ & $\begin{array}{l}\text { Depth } \\
\text { of cut }(\mathrm{mm})\end{array}$ \\
\hline $100 \mathrm{MPa}$ & $05 \mathrm{~F} 100$ & 100 & 0.5 \\
& $05 \mathrm{~F} 200$ & 200 & \\
& $05 \mathrm{~F} 300$ & 300 & \\
& $05 \mathrm{~F} 400$ & 400 & 1 \\
$100 \mathrm{MPa}$ & $1 \mathrm{~F} 100$ & 100 & \\
& $1 \mathrm{~F} 200$ & 200 & 1 \\
& $1 \mathrm{~F} 300$ & 300 & \\
$200 \mathrm{MPa}$ & $1 \mathrm{~F} 400$ & 400 & \\
& $1 \mathrm{~F} 100$ & 100 & \\
& $1 \mathrm{~F} 200$ & 200 & \\
& $1 \mathrm{~F} 300$ & 300 & \\
& $1 \mathrm{~F} 400$ & 400 & \\
\end{tabular}

A. Margarido et al.

\section{Results and discussion}

Samples were isostatically compacted between 100 and $200 \mathrm{MPa}$ for $30 \mathrm{~s}$ at maximum pressure in cylindrical dies, through a wet bag process. Figure 4 shows the images resulting from the granules after spray dryer and the green body surface after compaction at $100 \mathrm{MPa}$ (Fig. 4b) and at $200 \mathrm{MPa}$ (Fig. 4c). In the bottom position in contact with the metal wall of the die, it was observed by the shape of the deformed agglomerates that the higher compression applied (200 MPa) drastically reduced the empty spaces between the granules of alumina, which is indicative of the gain obtained in the densification by increasing the compaction. Kocjan et al. observed that the high packing density associated with microstructural homogeneity is a prerequisite for green bodies to ensure sintering temperatures low enough to minimize the grain growth [16].

Figure 5 shows the images of the green machined surfaces prior of sintering followed by images of scanning electron microscopy of the chip due to each machining parameter. The data collected through LabVIEW generated a list of torque vs time, concentrated in the last two machining steps.
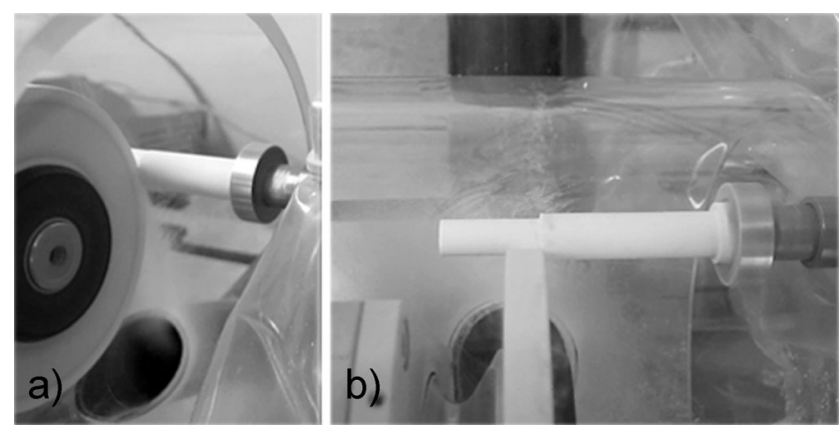

Fig. 3 Images of the machining operation, a side view and $\mathbf{b}$ top view 

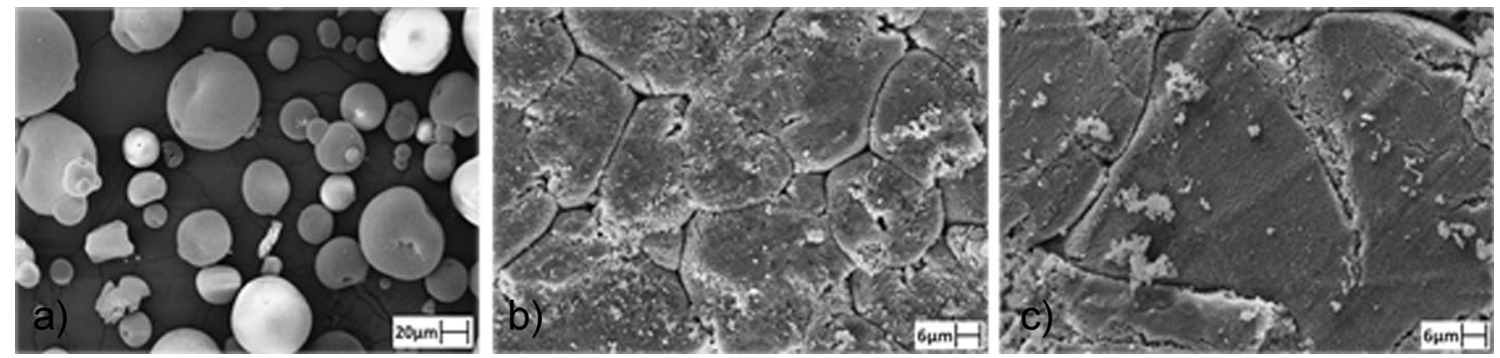

Fig. 4 Alumina granule stage, a spray dried, b compacted at $100 \mathrm{MPa}$, and c compacted at $200 \mathrm{MPa}$

Due to the semi-detached particles on the surface of the grinding wheel, which is common in dressing vitreous alloys, Fig. 5 allows better visualization and, consequently, interpretation of the improvement on the quality of the surface during the green machining with an increase in the tool feed speed. As evidenced by the reduction in the size of chips, it was further noticed that a distribution of scratches with lower depth on samples machined under the most aggressive grinding conditions was found to result in a small loss of strength as a function of increasing feed speed.

Samples with different treatments were compared in Fig. 6. The sample not treated was related to the compacted powder rested for $48 \mathrm{~h}$, and the treated sample was obtained after pressing, and kept in an oven at $100{ }^{\circ} \mathrm{C}$ for $12 \mathrm{~h}$. It can be observed in Fig. 6b, $d$ that the chips of the thermal treated samples are significantly lower than Fig. 6a, c, respectively, not treated, which sets the machining as intra-granular with little structural damage to the workpieces.

The mechanical strength of the same material processed with the same machining parameters $(0.5 \mathrm{~mm}$ in depth of cut and feed speed of $100 \mathrm{~mm} / \mathrm{min}$ ) was compared. Figure 7 shows the significant gain in structural strength to the samples, where a greater compaction force and a thermal annealing treatment were applied. The average compressive strength of the specimens compacted at $200 \mathrm{MPa}$ was significantly higher. The specimens not treated compacted at $100 \mathrm{MPa}$ presented $155 \mathrm{MPa}$, while the ones thermal annealed compacted
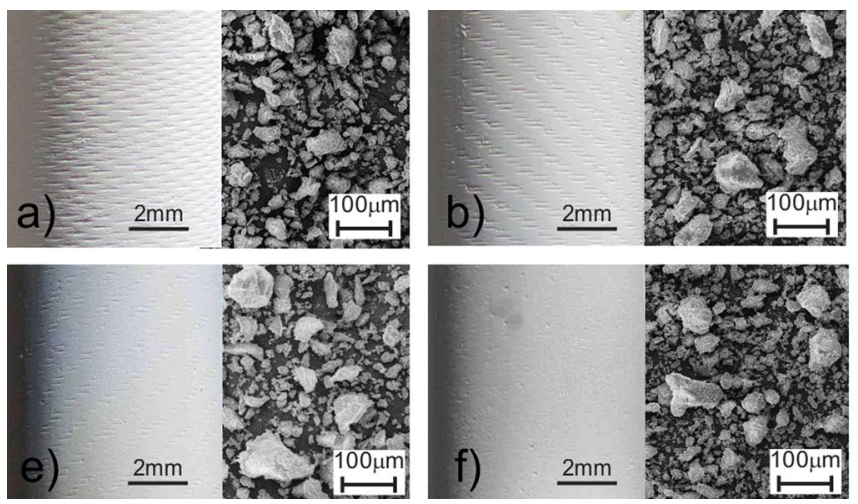

Fig. 5 Images of the surface from pieces compacted at $100 \mathrm{MPa}$, thermal annealed, and machined with different conditions, a feed speed of $100 \mathrm{~mm} / \mathrm{min}$ and depth of cut $0.5 \mathrm{~mm}$, b feed speed of $200 \mathrm{~mm} / \mathrm{min}$ and depth of cut $0.5 \mathrm{~mm}, \mathbf{c}$ feed speed of $300 \mathrm{~mm} / \mathrm{min}$ and depth of cut at $100 \mathrm{MPa}$ presented $326 \mathrm{MPa}$ and compacted at $200 \mathrm{MPa}$ had a compressive strength of $399 \mathrm{MPa}$. As pointed by Bowen et al., after compacting the resultant, green body microstructures can possess two types of pores, which were inter- and intra-"agglomerate" pores [17]. During sintering, the elimination of the inter-agglomerate pores needs high temperatures, so the compacts pressed at lower pressure contain more pores at same sintering temperature presenting a reduced mechanical strength. On the other hand, thermal treatment above the $T_{g}$ that acted as an annealing provides greater plasticity on the polymer film and a decrease in stress concentration. It should be emphasized that the power consumed for machining parts without treatment was 53 and $315 \mathrm{~W}$ for the treated ones; i.e., the untreated samples gave higher lubrication (adsorbed water), although the removal was more inter-granular with more surface defects, leading it to stick to the grinding wheel. The treated samples had a higher stiffness with an intra-granular removal mechanism. The thermal treatment above the PVA glass transition temperature $\left(T_{g} 87-89^{\circ} \mathrm{C}\right)$, in addition to reducing residual moisture, also helped to relieve the residual stress generated during the compaction.

As observed in porcelain machining, no visible surface defects were detected during machining of porcelain, which was also pointed out earlier by the work of Fortulan et al. [15]. The difference from previous work lies in the machining head, which, in the present work, uses aerostatic bearings, where noises and vibrations were greatly reduced and with a higher

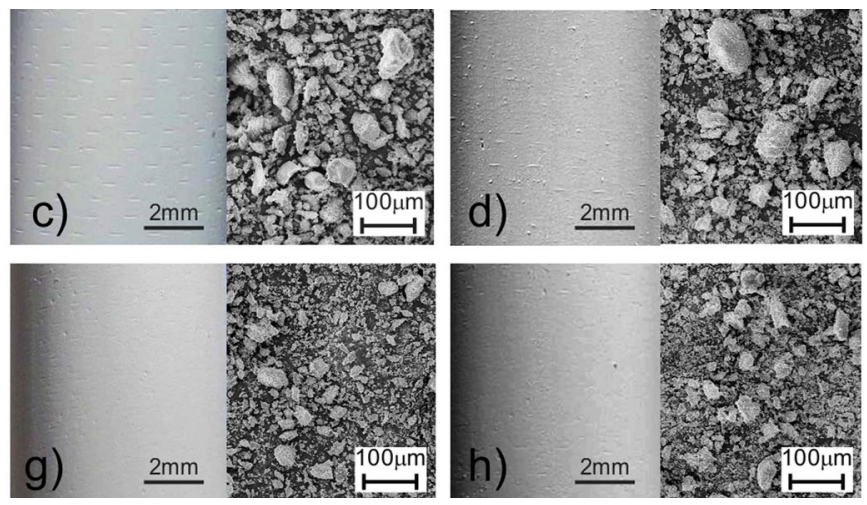

$0.5 \mathrm{~mm}, \mathbf{d}$ feed speed of $400 \mathrm{~mm} / \mathrm{min}$ and depth of cut $0.5 \mathrm{~mm}$, e feed speed of $100 \mathrm{~mm} / \mathrm{min}$ and depth of cut $1 \mathrm{~mm}$, f feed speed of $200 \mathrm{~mm} / \mathrm{min}$ and depth of cut $1 \mathrm{~mm}, \mathbf{g}$ feed speed of $300 \mathrm{~mm} / \mathrm{min}$ and depth of cut $1 \mathrm{~mm}$, and $\mathbf{h}$ feed speed of $400 \mathrm{~mm} / \mathrm{min}$ and depth of cut $1 \mathrm{~mm}$ 

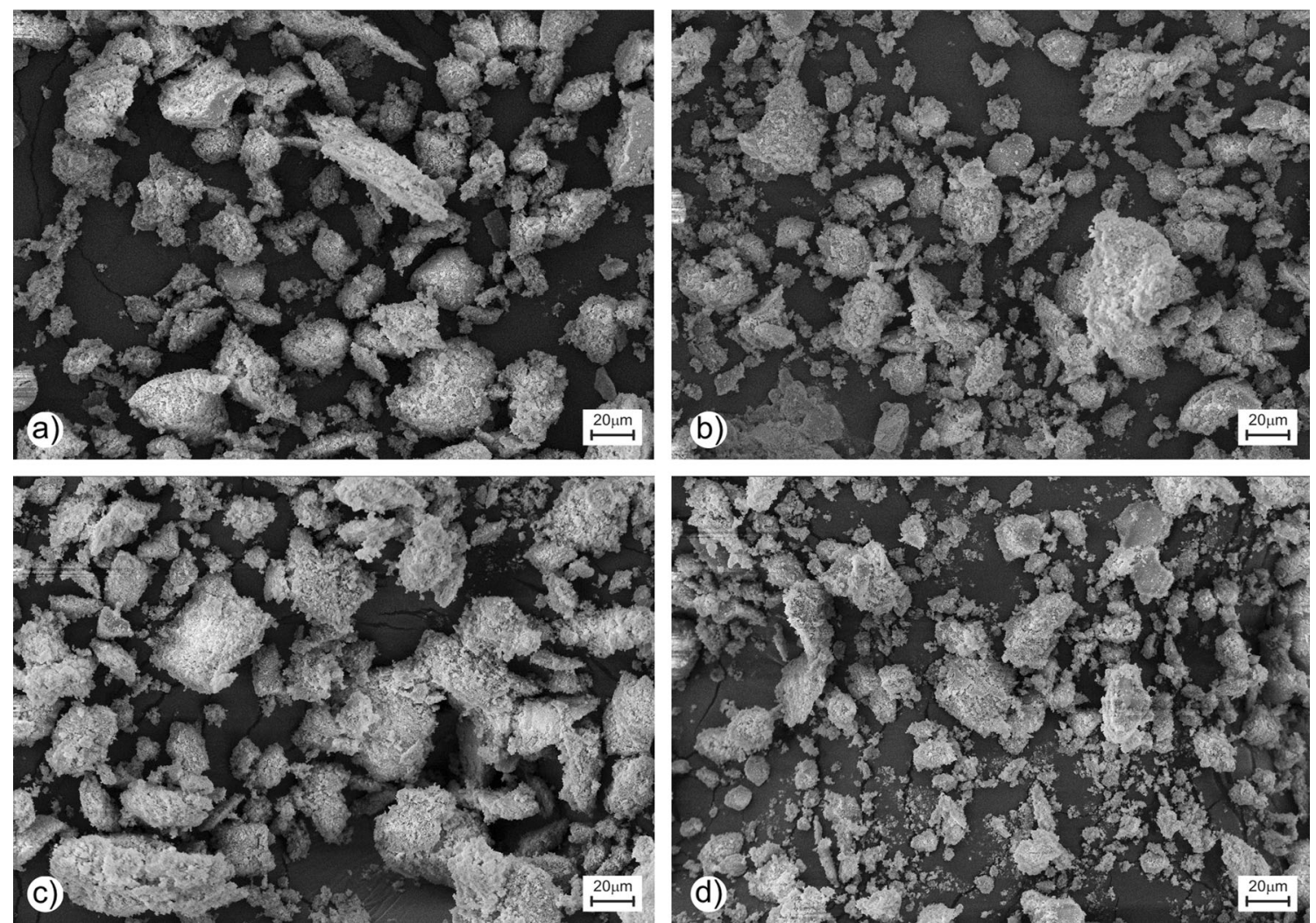

Fig. 6 Images of the chipping of machining specimens with feed speed of $100 \mathrm{~mm} / \mathrm{min}$ and depth of cut of $0.5 \mathrm{~mm}$, a compacted at $100 \mathrm{MPa}$ not thermal treated, b compacted at $100 \mathrm{MPa}$ thermal treated, c compacted at $200 \mathrm{MPa}$ not thermal treated, and d compacted at $200 \mathrm{MPa}$ thermal treated

power of $2400 \mathrm{~W}$, rather than the $500 \mathrm{~W}$ used on the previous work. Another difference was the use of spray dried powder with an average particle size of $0.4 \mu \mathrm{m}$ avoiding the machining on the intra-granular regime.

The torque measurement was taken from the average of points at the bottom of the plot (torque vs time) obtained by

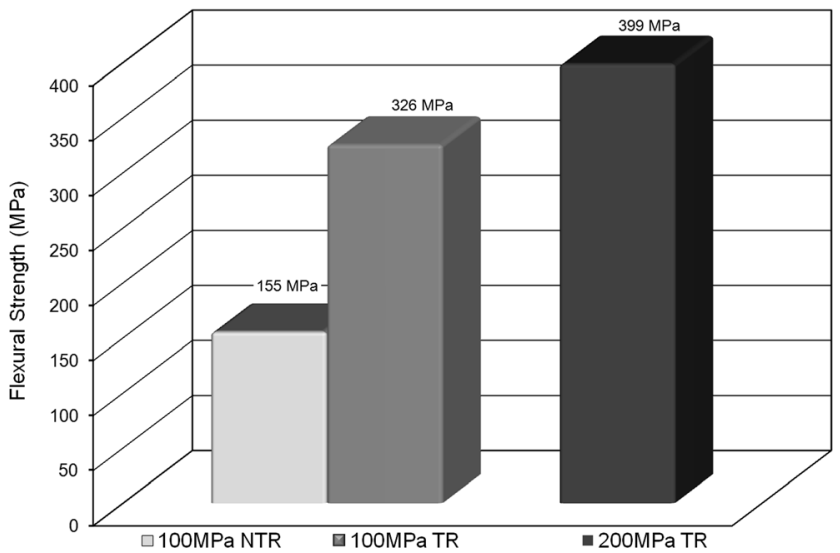

Fig. 7 Comparative chart of mechanical four-point flexural strength for bodies pressed at $100 \mathrm{MPa}$ not thermal treated, pressed at $100 \mathrm{MPa}$ thermal treated, and pressed at $200 \mathrm{MPa}$ thermal treated the sensor MK-01, adopted as a standby region and the average of the five highest peaks of torque as seen in Fig. 8. It was assumed that the torque peaks were responsible for the introduction of the critical defects.

In Fig. 9, the mechanical strength of the sintered samples, compacted at 100 and $200 \mathrm{MPa}$, were compared as a function of material removal rate for the depth of cut of 0.5 and $1.0 \mathrm{~mm}$. It was observed that at an increasing feed speed, the mechanical properties (flexural strength) were improved, which could be related to the surface finish due to the appearance of critical surface defects at low feed speed shown in Fig. 9a, b. However, a limit feed speed equal to $400 \mathrm{~mm} /$ min for the compacted bodies at $100 \mathrm{MPa}$ was found as observed by the increase in the standard deviation error bars. When this limit was exceeded, an unstable region, where a catastrophic rupture of the bodies occurred during the course of the grinding wheel in undefined positions, was noted. This was due to the cutting forces that exceeded the mechanical strength of the bodies, leading to breakage.

In Fig. 10, the power consumption in watts was compared against the material removal rate in $\mathrm{mm}^{3} / \mathrm{min}$ during the machining process. An increase in torque with the increase in feed speed and also with the depth of cut or some similarity 
Fig. 8 Plot torque vs time, a the entire spectrum and $\mathbf{b}$ selected stage. The lowest points represent the rest position and the average of the highest five points, the maximum torque a)

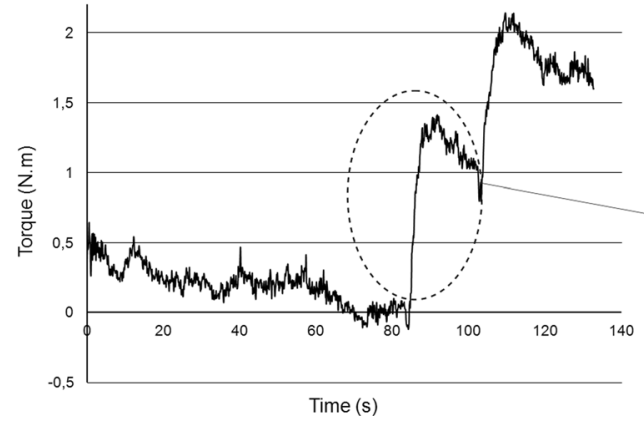

b)

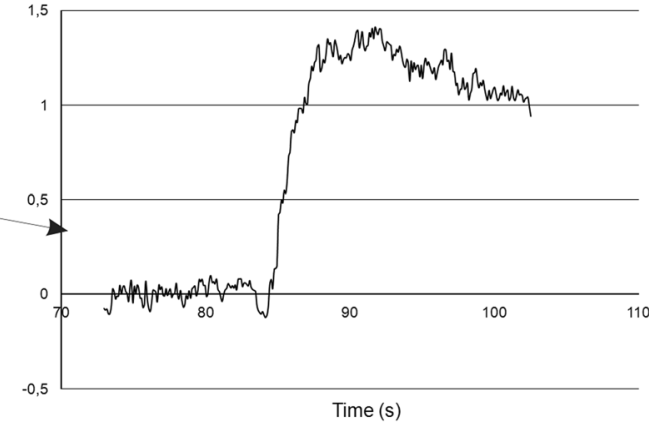

a)

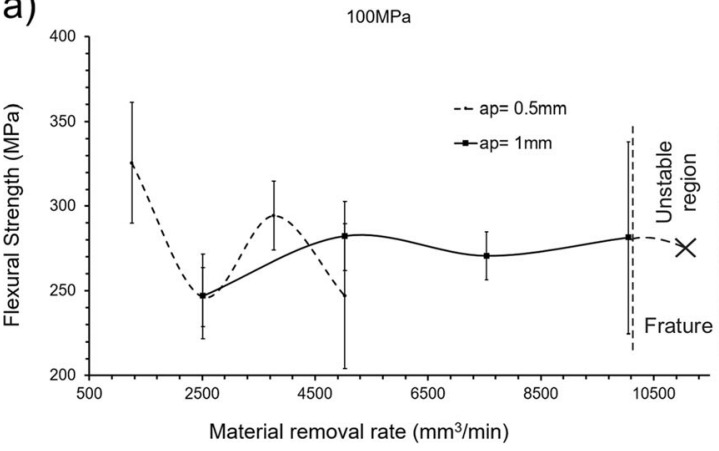

b)

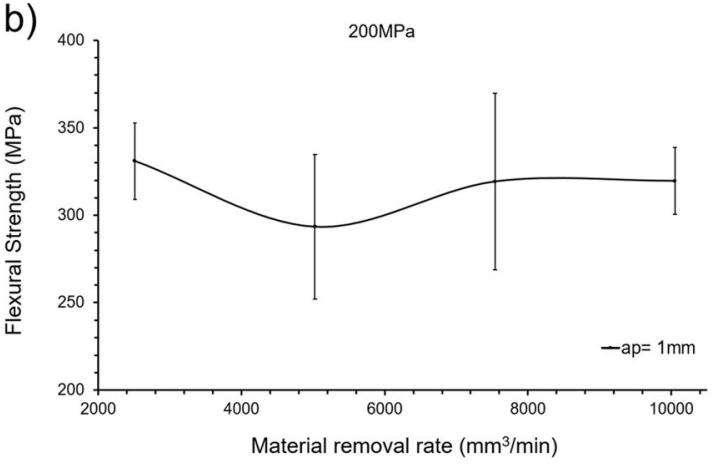

Fig. 9 Mechanical strength of the sintered samples as a function of the material removal rate, a samples pressed at $100 \mathrm{MPa}$ and $\mathbf{b}$ samples pressed at $200 \mathrm{MPa}$

with the material removal rate independent of the conditions (feed rate speed and depth of cut) could also be noted.

The flexural strength of the specimen pressed at $100 \mathrm{MPa}$ and sintered was only slightly affected with the increasing depth of cut $\left(a_{p}\right) ; 278 \pm 29 \mathrm{MPa}$ against 270 $\pm 29 \mathrm{MPa}$ for $a_{p} 0.5$ and $a_{p} 1 \mathrm{~mm}$ was found, respectively, using the same machining parameters. A loss of resistance of less than $3 \%$ can be neglected, however, based on the standard deviation.

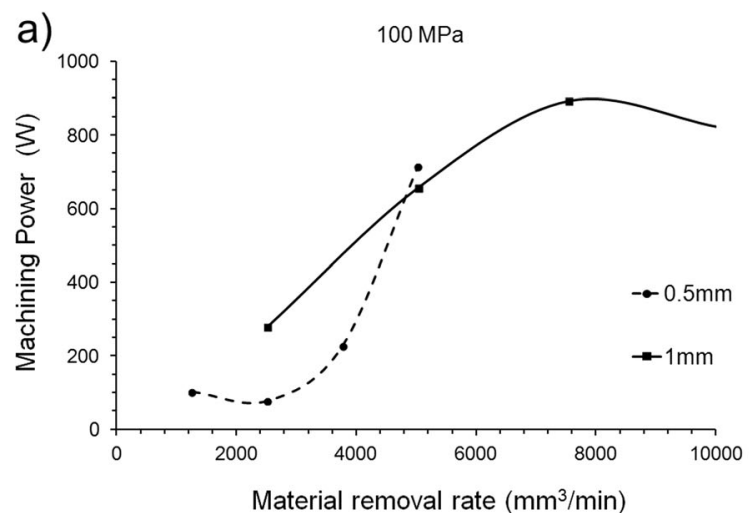

Figure 11 shows the images of the fractures of the sintered samples tested in a four-point flexural test. The specimen (Fig. 11a) with the lowest value of mechanical strength $(250 \mathrm{MPa})$ and specimen (Fig. 11b) with the highest (350 MPa) were the extremes of the batch 2-100 MPa$1 \mathrm{~F} 400$. The arrows indicate the beginning of the crack, where several deviations could be observed in the crack propagation.

Table 2 displays the average data of five samples of each machining parameter, where depth of cut and feed speed of the

b)

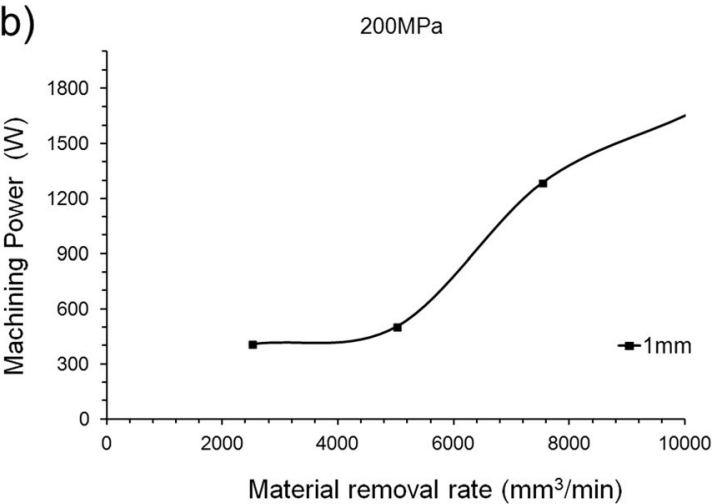

Fig. 10 Machining power consumption as a function of material removal rate, a specimens compacted at $100 \mathrm{MPa}$ and b specimens compacted at $200 \mathrm{MPa}$ 
Fig. 11 Fracture view of sintered samples compacted at $100 \mathrm{MPa}$, a specimen with the lowest value of mechanical strength $(250 \mathrm{MPa})$ and $\mathbf{b}$ the highest value $(350 \mathrm{MPa})$
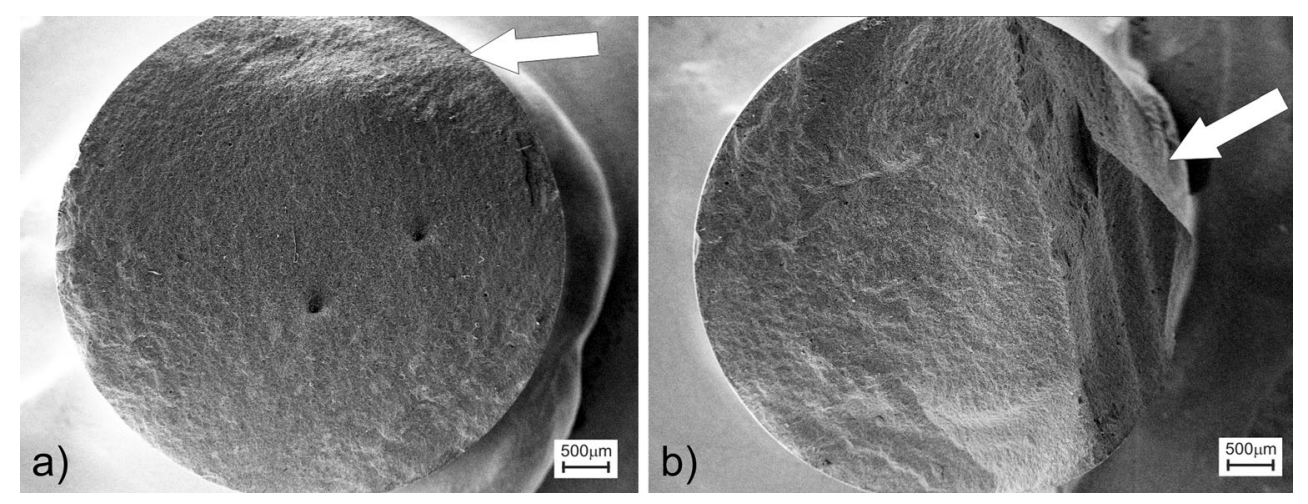

Table 2 Results of different machining parameters on the green grinded alumina

\begin{tabular}{|c|c|c|c|c|c|c|}
\hline $\begin{array}{l}\text { Compaction } \\
\text { pressure (MPa) }\end{array}$ & $\begin{array}{l}\text { Feed speed, } v_{f} \\
(\mathrm{~mm} / \mathrm{min})\end{array}$ & $\begin{array}{l}\text { Depth of cut, } \\
a_{p}(\mathrm{~mm})\end{array}$ & $\begin{array}{l}\text { Machining } \\
\text { power (W) }\end{array}$ & $\begin{array}{l}\text { Flexural } \\
\text { average } \\
(\mathrm{MPa})\end{array}$ & $\begin{array}{l}\text { Material } \\
\text { removal } \\
\text { rate, } Q \\
\left(\mathrm{~mm}^{3} / \mathrm{min}\right)\end{array}$ & $\begin{array}{l}\text { Torque } \\
(\mathrm{Nm})\end{array}$ \\
\hline \multirow{9}{*}{100} & & 0.5 & $76^{\mathrm{a}}$ & $155 \pm 25^{\mathrm{a}}$ & 1,256 & $0.06 \pm 0.01$ \\
\hline & 100 & 0.5 & 101 & $326 \pm 36$ & 1,256 & $0.09 \pm 0.04$ \\
\hline & & 1.0 & 278 & $247 \pm 25$ & 2,513 & $0.23 \pm 0.03$ \\
\hline & 200 & 0.5 & 76 & $246 \pm 18$ & 2,513 & $0.02 \pm 0.06$ \\
\hline & & 1.0 & 656 & $282 \pm 20$ & 5,026 & $0.55 \pm 0.03$ \\
\hline & 300 & 0.5 & 226 & $294 \pm 20$ & 3,770 & $0.19 \pm 0.02$ \\
\hline & & 1.0 & 892 & $271 \pm 14$ & 7,540 & $0.75 \pm 0.05$ \\
\hline & 400 & 0.5 & 712 & $247 \pm 43$ & 5,026 & $0.60 \pm 0.01$ \\
\hline & & 1.0 & 821 & $281 \pm 57$ & 10,053 & $0.69 \pm 0.10$ \\
\hline \multirow{5}{*}{200} & 100 & 0.5 & 386 & $399 \pm 86$ & 1,256 & $0.32 \pm 0.06$ \\
\hline & & 1.0 & 409 & $331 \pm 22$ & 2,513 & $0.34 \pm 0.06$ \\
\hline & 200 & 1.0 & 506 & $293 \pm 42$ & 5,026 & $0.42 \pm 0.03$ \\
\hline & 300 & 1.0 & 1286 & $319 \pm 50$ & 7,540 & $1.08 \pm 0.03$ \\
\hline & 400 & 1.0 & 1657 & $320 \pm 19$ & 10,053 & $1.39 \pm 0.01$ \\
\hline
\end{tabular}

A. Margarido et al.

${ }^{\text {a }}$ Not thermal treated before machining tool were changed. The power consumed was obtained by correlation with torque.
During the tests, a discontinuity in the mechanical strength of machined bodies with feed rate of $200 \mathrm{~mm} / \mathrm{min}$ was noticed
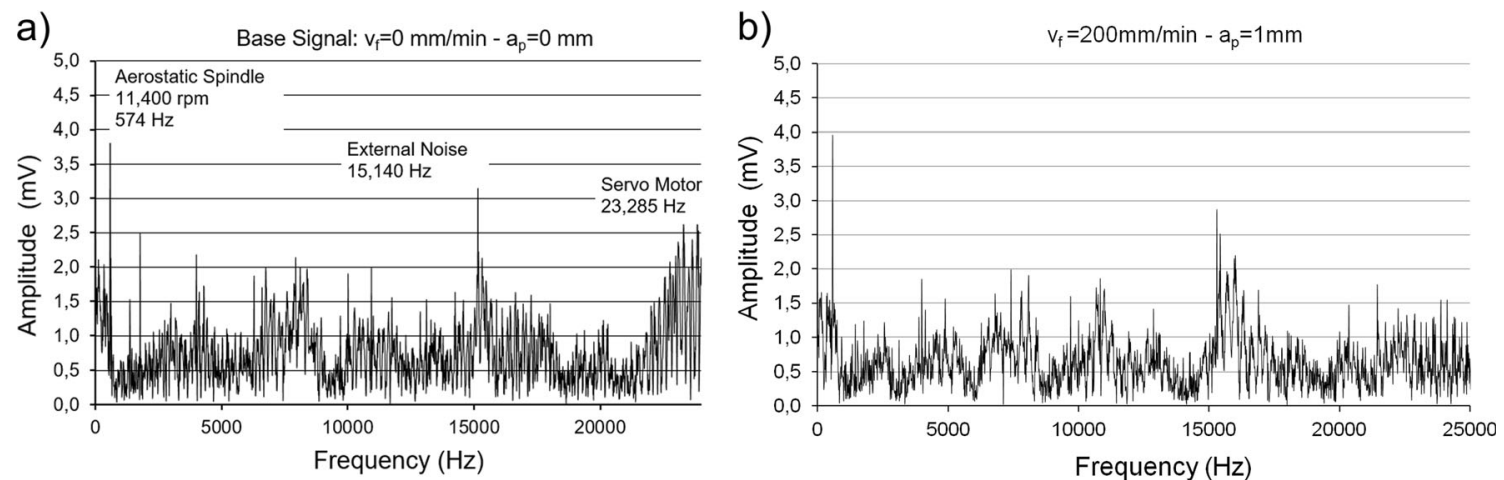

Fig. 12 Vibration analysis, a base signal equipment connected without machining operation and $\mathbf{b}$ during the green machining with depth of cut $\left(a_{p}\right)$ of $0.5 \mathrm{~mm}$ and feed speed $\left(v_{f}\right)$ of $=200 \mathrm{~mm} / \mathrm{min}$ 
( $Q$ of $2500 \mathrm{~mm}^{3} / \mathrm{min}$; Fig. 9a), which indicated a possible interference caused by the machining equipment. Therefore, experiments with an accelerometer fixed on the tool holder were performed for measuring the vibration in the headstock of the machine in all machining conditions in the search for a possible resonance condition. In Fig. 12a, the natural vibration of the machine at the stand-up condition with all engines running was identified. Figure $12 \mathrm{~b}$ plots the behavior at feed rate of $200 \mathrm{~mm} / \mathrm{min}$ and $a_{p}$ of $0.5 \mathrm{~mm}$, and any significant vibratory event to explain the drop of mechanical strength was not observed, which could be assigned to a compromise between gain in surface quality by increasing the feed speed and loss due to the increased cutting forces. Therefore, atypical vibratory event was attributed to experimental combination of machining events.

\section{Conclusions}

The green machining, performed on the developed test bench, based on external cylindrical grinding, assembled with aerostatic bearings on the head (very low noise); optimized conditions of feed speed and depth of cut; controlled processing powder, compaction, and treatment; and generated sintered bodies with average flexural strength of $399 \mathrm{MPa}$. This level of value is consistent with the published literature values related to polished advanced alumina ceramic, validating the green machining as a manufacturing method for highperformance parts.

The experiments indicated that flexural strength of sintered bodies was independent of the increase of feed speed to reach a limit that resulted in the rupture of the specimen, when the mechanical strength of green rod was exceeded. For bodies compacted at $100 \mathrm{MPa}$, an unstable region before the limit due inter-granule failure was found.

The necessity of a thermal annealing on the blank after pressing was evident since it promoted a significant increase in the flexural strength of sintered bodies, increasing the strength of the bodies compacted at $100 \mathrm{MPa}$ from 155 to $325 \mathrm{MPa}$. These results reinforce the need for additional works evaluating other types of binders and thermal-treated conditions, for instance, acrylics.

The best value of sintered bodies was found for blanks compacted at $200 \mathrm{MPa}$, thermal treated after pressing at $100{ }^{\circ} \mathrm{C}$ for $12 \mathrm{~h}$, and machined with feed speed of $100 \mathrm{~mm} /$ min and depth of cut of $0.5 \mathrm{~mm}$, which reached average strength of $399 \mathrm{MPa}$.

The present experimental conditions on the blanks compacted at $200 \mathrm{MPa}$, a material removal rate of $10,000 \mathrm{~mm}^{3} / \mathrm{min}$ with a peak power consumption of $1700 \mathrm{~W}$, was achieved as the best cost/benefit ratio, and this information is considered critically important for the design of ceramic green-machining equipment.
Acknowledgments The authors gratefully acknowledge the financial support of Conselho Nacional de Desenvolvimento Científico e Tecnológico (CNPq) (Contract No. 479041/2009-1), Institute of BioFabrication (INCT-BIOFABRIS), and to Coordenação de Aperfeiçoamento de Pessoal de Nível Superior (CAPES) for the scholarship granted.

\section{Compliance with ethical standards}

Conflict of interest The authors declare that they have no conflict of interest.

\section{References}

1. Mohanty S, Rameshbabu AP, Dhara S (2013) Net shape forming of green alumina via $\mathrm{CNC}$ machining using diamond embedded tool. Ceramics International 39:8985-8993. doi:10.1016/j. ceramint.2013.04.099

2. Rahaman M, Yao A, Bal B, Garino J, Ries M (2007) Ceramics for prosthetic hip and knee joint replacement. J Am Ceram Soc 90(7): 1965-1988. doi:10.1111/j.1551-2916.2007.01725.x

3. Mohanty S, Rameshbabu AP, Mandal S, Bo S, Dhara S (2013) Critical issues in near net shape forming via green machining of ceramics: a case study of alumina dental crown. Journal of Asian Ceramic Societies 1:274-281

4. Su B, Dhara S, Wang L (2008) Green ceramic machining: a topdown approach for the rapid fabrication of complex-shaped ceramics. J Eur Ceram Soc 28(11):2109-2115. doi:10.1016/j. jeurceramsoc.2008.02.023

5. Li J-Z, Wu T, Yu Z-Y, Zhang L, Chen G-Q, Guo D-M (2012) Micro machining of pre-sintered ceramic green body. Journal of Materials Processing Technology 212:571-579

6. Cawley JD (1999) Solid freeform fabrication of ceramics. Current Opinion in Solid State \& Materials Science 4(5):483-489. doi:10.1016/s1359-0286(99)00055-8

7. Bukvic G, Sanchez LEA, Fortulan CA, Fiocchi AA, Marinescu ID (2012) Green machining oriented to diminish density gradient for minimization of distortion in advanced ceramics. Machining Science and Technology 16:228-246. doi:10.1080 /10910344.2012.673968

8. Filser F, Kocher P, Weibel F, Luthy H, Scharer P, Gauckler LJ (2001) Reliability and strength of all-ceramic dental restorations fabricated by direct ceramic machining (DCM). Int J Comput Dent 4(2):89-106

9. Kamboj RK, Dhara S, Bhargava P (2003) Machining behaviour of green gelcast ceramics. J Eur Ceram Soc 23:1005-1011. doi:10.1016/S0955-2219(02)00265-0

10. Chabert F, Dunstan DE, Franks GV (2008) Cross-linked polyvinyl alcohol as a binder for gelcasting and green machining. Journal of the American Ceramic Society 91(10):3138-3146. doi:10.1111 j.1551-2916.2008.02534.x

11. Reed JS (1995) Principles of ceramics processing, 2nd edn. WileyInterscience, New York, pp 628-633

12. Wu XLKW, Mcanany WJ (1995) Acrylic binder for green machining. American Ceramic Society Bulletin 74(5):61-64

13. Jahanmir S, Produktionstech VG (1996) Mechanisms of material removal in the grinding of advanced ceramics, 2nd edn., pp 159 173, International Conference on Machining of Advanced Materials (Mam)

14. Desfontaines M, Jorand Y, Gonon M, Fantozzi G (2005) Characterization of the green machinability of AlN powder 
compacts. Journal of the European Ceramic Society 25(6):781791. doi:10.1016/j.jeurceramsoc.2004.03.006

15. Fortulan C, Gambale B, Chinelatto A, Purquerio B (2011) Influence of alumina content on green machined electrical porcelain. Industrial Ceramics 31(2):137-143

16. Kocjan A, Pouchly V, Shen J (2015) Processing of zirconia nanoceramics from a coarse powder. Journal of the European
Ceramic Society 35:1285-1295. doi:10.1016/j. jeurceramsoc.2014.10.022

17. Bowen P, Carry C (2002) From powders to sintered pieces: forming, transformations and sintering of nanostructured ceramic oxides. Powder Technology 128(2-3):248-255. doi:10.1016 /S0032-5910(02)00183-3 